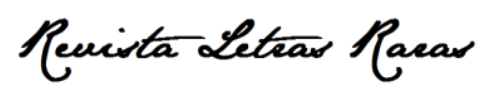

ISSN: 2317-2347 - v. 10, n. 4 (2021)

Todo o conteúdo da RLR está licenciado sob Creative Commons Atribuição 4.0 Internacional

\title{
A análise de necessidades perante o caráter hercúleo de uma tarefa premente: tornar o ensino de Inglês como Língua Estrangeira na educação superior uma prática centrada no aluno / Needs Analysis before the Herculean nature of an urgent task: to render English as a Foreign Language teaching at higher education a student-centered practice
}

José Vicente Santos Mendes*

Mestre em ciências linguística teórica pela Sophia University, Tokyo, Japan. PhD em linguística cognitiva pela Hamburg Universität, Alemanha. Decano de Inglês Língua Estrangeira da Universidade Federal do Sul da Bahia.

(iD) https://orcid.org/0000-0002-6629-0421

Recebido em: 01 set. 2021. Aprovado em: 31 out. 2021.

\section{Como citar este ensaio:}

MENDES, José Vicente Santos. A análise de necessidades perante o caráter hercúleo de uma tarefa premente: tornar 0 ensino de Inglês como Língua Estrangeira na educação superior uma prática centrada no aluno. Revista Letras Raras, Campina Grande, v. 10, n. 4, p. 217-236, dez. 2021.

\section{RESUMO}

Este ensaio acadêmico tem um triplo objetivo: Rever a bibliografia mais relevante desde os clássicos até os dias atuais sobre 0 instrumento metodológico 'análise de necessidades'. Apresentar, respaldado por essa literatura pertinente revisitada, a face de Jano da minha prática docente concernente ao tema em tela: por um lado, a obrigação de formatar cada curso de Inglês Língua Estrangeira (ILE) que for ministrar para as especificidades desse ou daquele alunado, a partir da sondagem de uma análise de necessidades; e por outro, a factibilidade dessa demanda avassaladora, que inviabiliza, por enquanto, tal customização pormenorizada. Corolário, apresentar uma $3^{\mathrm{a}}$ via para o dilema, pressionado que sou a optar por um Inglês Geral para Fins Específicos, devido tanto à complexidade do planejamento curricular em si, quanto à ubiquidade do papel do inglês no modelo institucional que a universidade em que ora atuo adota, e seu plantel hoje na área, ainda deveras escasso.

PALAVRAS-CHAVE: Análise de Necessidades; Inglês como Língua Estrangeira; Universidade pública federal; Inglês Geral para Fins Específicos.

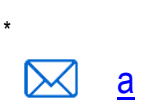




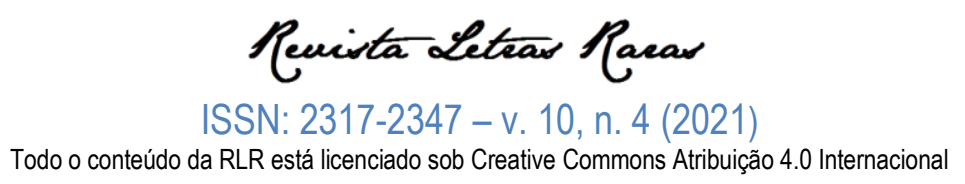

ABSTRACT

This academic essay has three aims: To review the most relevant bibliography, ranging from the classics up to nowadays, on the methodological tool 'needs analysis'. To present, based on this revisited pertinent literature, the Janus face of my teaching practice concerning the topic at issue: on the one hand, the obligation to format each syllabus of English as a Foreign Language (EFL) I teach on the specificities of each group of students, after a needs analysis survey; on the other hand, the overwhelming quality of this demand, that prevents, for now, such tailor-cut customization. Corollary, to propose a $3^{\text {rd }}$ via to the dilemma, being pressed to opt for a General English for Specific Purposes, due not only to the complexity of course design itself, but also to the ubiquitous role English plays in the institutional model my home university adopts, and its current staff in the area, still quite scarce.

KEYWORDS: Needs Analysis; English as a Foreign Language; Public federal university; General English for Specific Purposes.

\section{Introdução}

Este ensaio acadêmico tece ponderações a respeito da realidade laboral que me toca enquanto professor de ILE (Inglês Língua Estrangeira) na UFSB, desdobrando o que Mendes (2018) pontua. A estrutura do texto será a seguinte: fazer um levantamento de marcos na literatura de Linguística Aplicada no que tange ao tópico 'Análise de Necessidades' e sua desejabilidade anterior a toda e qualquer prática docente de língua estrangeira; listar os itens que tornam a implementação hoje de um desenho customizado de planos de curso, a partir de uma sondagem de Análise de Necessidades no meu cotidiano trabalhista bastante dificultosa; e, finalmente, tentar um acordo possivel entre os dois lados dessa moeda, buscar um ponto de equilibrio para esse cabo de força como uma solução paliativa para a contenda, qual seja, a adoção de uma abordagem guarda-chuva concernente ao inglês para propósitos acadêmicos que resolvi chamar de "Inglês Geral para Fins Específicos".

\section{Do conceito 'Análise de Necessidades' e da sua evolução na literatura de Linguística Aplicada: visão panorâmica}

Há pelo menos 40 anos, desde Munby (1978), a Análise de Necessidades vem sendo tematizada pelos teóricos do ensino de línguas. Intuitivamente, poderíamos dizer que o termo se refere à avaliação/determinação das necessidades dos aprendizes, servindo de ferramenta para se conceber um ensino da língua-alvo que seja eficaz para esse alunado especificamente. Mais tecnicamente, segundo Richards e Schmidt (2010):

Análise de necessidades (...) é o processo de determinar as necessidades pelas quais um aprendiz ou grupo de aprendizes demanda uma língua e de organizar 


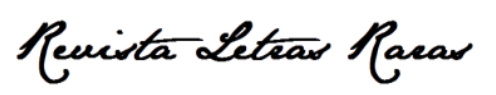

ISSN: 2317-2347 - v. 10, n. 4 (2021)

Todo o conteúdo da RLR está licenciado sob Creative Commons Atribuição 4.0 Internacional

essas necessidades de acordo com prioridades. O processo faz uso de informação tanto subjetiva quanto objetiva (ex. dados de questionários, testes, entrevistas, observação) e procura obter informação sobre: a. a situação na qual a língua será usada (incluindo com quem ela será usada); b. os objetivos e propósitos pelos quais se precisa da língua; c. os tipos de comunicação que serão usados (ex. escrita, falada, formal, informal); d. o nível de proficiência que será requerido. A análise de necessidades é uma parte da concepção ou do desenho curricular e normalmente é exigida antes que um plano de curso possa ser elaborado para 0 ensino da língua1. (RICHARDS; SCHMIDT, 2010, p. 389-390)

\section{McDonough (1999, p. 228) assim introduz o verbete no Dicionário Enciclopédico de Linguística}

Aplicada, antes de discorrer sobre os pontos em contenda que o termo técnico abarca:

Análise de necessidades é um termo que ganhou proeminência durante a década de 70. Embora não seja co-extensivo com ele, o conceito se desenvolveu em consonância com uma formulação de uma ABORDAGEM COMUNICATIVA no ensino de línguas. Tem sido particularmente associado ao campo de Inglês para Fins Específicos, no qual tem sido exaustivamente discutido e modificado a partir das perspectivas tanto do princípio quanto da prática.

Expresso em termos genéricos, a identificação das necessidades linguísticas 'consiste primariamente em compilar informação tanto sobre os indivíduos ou grupos de indivíduos que estão prestes a aprender a língua, tanto quanto sobre 0 uso que se espera que farão dela quando a tiverem aprendido' (Richterich, 1983, p. 2). Em outras palavras, os procedimentos associados com a análise de necessidades oferecem àquela pessoa que se propõe a desenhar um curso 0 arcabouço para a seleção de conteúdo linguístico de acordo com os objetivos dos aprendizes em particular (vide INDIVIDUALIZAÇÃO) e, consequentemente, a possibilidade de criar programas "sob medida", em vez de começar com um plano de curso já pronto, que por si mesmo não discrimina entre objetivos diferentes [de estudantes diferentes entre si]. Por trás dessas observações objetivas e diretas, entretanto, existem um sem número de abordagens diversas e um certo grau de controvérsia. ${ }^{2}$ (MCDONOUGH, 1999, p. 228)

1 Tradução minha do original em inglês, pela qual optarei ao longo de todo o texto. Transcrevendo a fonte primária, temos:
"Needs analysis (in language teaching and language programme design) is the process of determining the needs for which
a learner or group of learners requires a language and arranging the needs according to priorities. It makes use of both
subjective and objective information (e.g. data from questionnaires, tests, interviews, observation) and seeks to obtain
information on: a. the situations in which a language will be used (including who it will be used with); b. the objectives and
purposes for which the language is needed; c. the types of communication that will be used (written, spoken, formal,
informal) and d. the level of proficiency that will be required. Needs analysis is a part of curriculum design or conception,
and is normally required before a course syllabus can be developed for any language teaching."
2 Transcrevendo a fonte primária, temos: "needs analysis is a term which gained prominence during the 1970s. Although
not coterminous with it, the concept developed alongside the formulation of a COMMUNICATIVE APPROACH to language
teaching. It has been particularly associated with the field of English for Specific Purposes (ESP), where it has been
extensively discussed and modified from the perspectives of both principle and practice. Expressed in general terms, the
identification of language needs 'consists primarily in compiling information both on the individuals or groups of individuals
who are to learn a language and on the use which they are expected to make of it when they have learnt it' (Richterich,
1983, p. 2). In other words, the procedures associated with the analysis of needs offer the course designer a framework for 


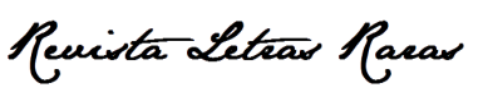

ISSN: 2317-2347 - v. 10, n. 4 (2021)

Todo o conteúdo da RLR está licenciado sob Creative Commons Atribuição 4.0 Internacional

E o teórico em Linguística Aplicada desdobra o verbete listando o que grandes pensadores no ramo propuseram quanto ao termo técnico 'análise de necessidades' nas décadas de 70 e 80 . Ficam aqui as recomendações de leitura para quem quiser percorrer um caminho mais historicista da quase genealogia do termo técnico em pauta. Contudo, não entrarei mais nesses detalhes de forma pormenorizada, por conta do desejável caráter breve que prepondera sobre a produção de qualquer gênero acadêmico na contemporaneidade: Pilbeam (1979), Chambers (1980), Richterich e Chancerel (1980), Hawkey (1983), Markee (1986), Coleman (1988), e West (1994), para citar só os que não foram já referenciados previamente ao longo deste ensaio.

Todavia, sem revelar a moral de cada estória, e, ao mesmo tempo, prezar por atribuir o devido mérito a essas ponderações primeiras sobre o conceito que estiveram em evidência nas décadas de 70 e 80, decido por arrolá-las aqui, ainda que "telegraficamente", e de modo a deixar sob os holofotes algumas mais que outras, ou mesmo em detrimento de outras. Porém, antes disso, cumpre ressaltar que nada mais natural que o conceito de 'Análise de Necessidades' ter se desenvolvido em paralelo ao de 'Abordagem Comunicativa' de ensino-aprendizagem de línguas. Isso porque 0 uso real de qualquer língua natural se dá, no mais das vezes - salvo quando a função fática (Jakobson, 1969 apud Chalhub, 2006) da língua está em jogo - para preencher vazios ou desníveis informacionais entre os interactantes. Logo, soa quase autoexplicativo vermos o uso proficiente de uma língua estrangeira também envolvendo precipuamente competências e habilidades que levem os utentes a atingirem esse mesmo objetivo.

Agora sim, podemos listar sumariamente os destaques que McDonough (1999) arrola na evolução do termo técnico 'Análise de Necessidades' durante as décadas de 70 e 80 . Então vejamos: citando como exemplos de necessidades distintas entre usuários com perfis de objetivos diferentes, McDonough (1999) enumera as demandas distintas quanto ao ILE de um estudante de pósgraduação, em oposição a uma secretária executiva (trilíngue) e a um consultor para assuntos técnicos. Cada um, e assim sucessivamente, vai precisar do ILE diferentemente, e o foco aqui é nos fins em vez de ser nos meios. Em seguida, refere Munby (1978), que levanta a análise da situação

the selection of language content according to the goals of particular learners (see INDIVIDUALIZATION) and therefore the possibility of creating tailor-made programmes, rather than starting with a ready-made syllabus that does not of itself discriminate between different objectives [different students may have]. Behind these straightforward observations, however, are a number of different approaches and a certain degree of controversy." 


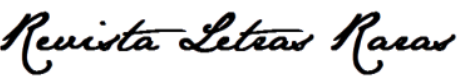

ISSN: 2317-2347 - v. 10, n. 4 (2021)

Todo o conteúdo da RLR está licenciado sob Creative Commons Atribuição 4.0 Internacional

alvo com base num processador de necessidades comunicativas. 0 contexto-alvo nesse autor é analisado em 8 categorias diferentes, resultando em uma paleta de habilidades e itens linguísticos apropriadas/os a cada subcategoria de contexto-alvo. Vem então a vez de Pilbeam (1979) ser mencionado, para quem the audit (a auditoria, inspeção, vistoria, o exame, o controle, o escrutínio) da situação-alvo levará à determinação das exigências referentes ao ILE para trabalhos/empregos específicos em uma empresa, medidos em contraposição à proficiência corrente de plantel, membros do $\mathrm{RH}$ relevantes para tal e tal função laboral. Sobre métodos para coletar dados referentes às necessidades alvo, várias possibilidades são listadas, e Mackay (1978) exemplifica algumas delas destacando questionários e entrevistas como as mais frequentes. Na última subseção do verbete, intitulada problemas/pontos de debate/temas para discussão/questões controversas chave envolvendo Análise de Necessidades, McDonough (1999) lista basicamente 3 tópicos, a partir do legado de Munby (1978) e Chambers (1980), no que diz respeito a uma compreensão mais aguçada na área do que uma análise de situação-alvo ainda não contemplava à época: A. Ao contrário do 'participante' de Munby (1978, p. 52), os aprendizes de língua não são meros pacotes de necessidades-alvo identificadas. Eles apresentam expectativas, exigências e desejos que podem redundar inconvenientes para um programa baseado em objetivos finais pragmaticamente delineados. Eles também terão percepções de suas próprias necessidades, que provavelmente mudarão ao longo do tempo, à medida que os objetivos de aprendizagem forem sendo redefinidos, em função de eles tomarem cada vez mais pé de seu próprio estágio atual de proficiência na L2. B. Há um número de outros atores no processo que terão suas próprias percepções de necessidades em um contexto particular, tais como: patrocinadores (sejam elas firmas privadas ou agências governamentais), o futuro local de trabalho ou departamento acadêmico que receberá o/a estudante, a instituição em que o programa de língua ocorre e os próprios professores de ILE. Nesse viés, Richterich e Chancerel (1980) oferecem uma perspectiva bem diferente da de Munby (1978), ao tratarem de um contexto em larga escala - o Conselho Europeu - e o seu esquema de como adultos em geral aprendem ILE com demandas diversas no cotidiano, a partir da perspectiva de cada aprendiz em particular. C. É bastante improvável que um curso de língua possa consistir somente de uma série de respostas derivadas de uma situação alvo. Tal ensino por objetivos ignora a realidade da situação de aprendizagem em si mesma e do processo cognitivo e comportamental, emotivo e intuitivo de aquisição de língua natural, 


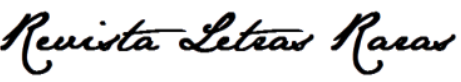

ISSN: 2317-2347 - v. 10, n. 4 (2021)

Todo o conteúdo da RLR está licenciado sob Creative Commons Atribuição 4.0 Internacional

seja ela L1 ou L2, língua materna ou língua adicional. Como será explicitado adiante, no modelo de Hutchinson e Waters (1987), uma pletora de fatores precisa ser levada em conta na dinâmica de ensino-aprendizagem de ILE: motivações, atitudes, interesses, razões pessoais para a aprendizagem, estilos de aprendizagem, além de recursos e janela temporal disponíveis. Em suma, a Análise de Necessidades é um processo complexo, que, usando dados de uma variedade de fontes, potencialmente leva em consideração uma ampla gama de variáveis tanto no que diz respeito ao contexto alvo quanto no que concerne ao ambiente de aprendizagem.

Como se pode notar, quando se fala em Linguística Aplicada de 'Análise de Necessidades', trata-se de um termo abrangente e poliédrico, multifacetado. Um dos modelos mais citados na literatura para o detalhamento desse termo é o de Hutchinson e Waters (1987). De acordo com esses autores, a Análise de Necessidades envolve duas dimensões: A análise da situação-alvo e a análise das necessidades de aprendizagem. $A$ análise da situação-alvo busca responder a várias perguntas: Por que a língua é necessária? Como a língua será usada? Quais serão as áreas de atuação? Com quem o aluno vai usar a língua? Onde e quando a língua será usada? Já a análise das necessidades de aprendizagem busca responder a outro conjunto de questões: Por que os alunos fazem o curso? Como os alunos aprendem? Quais as fontes disponíveis? Quem são os aprendizes? Onde e quando o curso será ministrado?

Um modelo alternativo ao de Hutchinson e Waters (1987) também muito referido na literatura é o de Dudley-Evans e St. John (1998). Esses teóricos propõem uma lista diferente de quesitos para subsidiar o levantamento de Análise de Necessidades: Tarefas e atividades em que os aprendizes usarão a língua inglesa; fatores que podem afetar a aprendizagem (experiência prévia de aprendizagem, informação cultural, expectativas quanto à língua-alvo...); habilidades e uso corrente da língua que serão avaliados; lacunas entre a situação atual e a situação-alvo; formas efetivas na situação de aprendizagem da língua; dados da comunicação profissional na situação-alvo; o que se deseja do curso e 0 ambiente no qual ele será ministrado.

Notem que muito do arcabouço de Dudley-Evans e St. John (1998) abre um leque investigativo que coincide, em grande parte, com o quadro teórico escopado por Hutchinson e Waters (1987), porém é mais detalhado em alguns pontos que esse modelo precursor. Afinal, aqui as questões abrangem desde a situação-alvo e as necessidades objetivas daí decorrentes, como informação pessoal sobre 


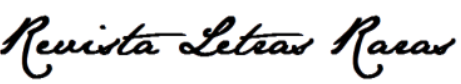

ISSN: 2317-2347 - v. 10, n. 4 (2021)

Todo o conteúdo da RLR está licenciado sob Creative Commons Atribuição 4.0 Internacional

os aprendizes, sua língua, o desnível do seu desempenho do momento atual para o momento pósaprendizagem (idealmente bem sucedida), e também informação sobre a aprendizagem da língua em geral, e a análise linguística, do discurso e de gênero envolvendo o uso da língua em situações concretas e áreas de conhecimento específicas, isto é, análise detalhada do contexto de uso real da língua-alvo em domínios particulares do saber.

A transição de um modelo para o outro reflete uma mudança de paradigma no que tange a como o antigo 'inglês instrumental' ou 'inglês técnico' ou ainda 'inglês de especialidade', é reconceptualizado enquanto 'inglês para fins específicos', 'inglês para fins ocupacionais', 'inglês para fins acadêmicos', 'inglês língua internacional', 'inglês língua franca/global/adicional/geral' etc. Conferir a respeito, entre outros, Robinson (1991), Ramos (2005), Celani (2008), Nash e Ferreira (2010), Siqueira (2011), Della Rosa (2013), Jordão (2014) e Thompson (2016), que retoma a categorização tradicional, como que numa volta às raízes, se me permitem.

Paltridge (2012) esmiúça o escopo guarda-chuva da nomenclatura ou categoria 'Inglês para Fins Específicos' e sua natureza. Para o pesquisador, o termo, seja em contexto de inglês como língua estrangeira ou em contexto de inglês como segunda língua, envolve tanto 'inglês para fins acadêmicos' quanto 'inglês para fins ocupacionais', incluindo ainda 'inglês para médicos', 'inglês para negócios'... 'inglês para ciência e tecnologia', 'inglês para fins vocacionais', e até o que Belcher (2009) chama de 'inglês para fins socioculturais'. O teórico reitera que o traço chave desse termo guarda-chuva, IFE, é que o conteúdo e os objetivos do curso são orientados para as necessidades específicas dos aprendizes, os quais costumam ser adultos e já ter um nível pelo menos intermediário da língua-alvo. Enfatizando que a Análise de Necessidades é a parte mais importante de qualquer curso de inglês para fins específicos, Paltridge (2012) vê dois componentes precípuos na dinâmica de Análise de Necessidades: necessidades alvo e necessidades de aprendizagem. Daí surgem a análise da situação-alvo (qual o conhecimento e quais as habilidades serão exigidos pelos papéis que os futuros aprendizes irão desempenhar para que cumpram essas tarefas a contento?) e a análise da situação de aprendizagem (verificar o que os aprendizes já conseguem fazer no início do curso, bem como informação sobre sua subjetividade, e as necessidades orientadas a processo que eles sintam nesse momento). 


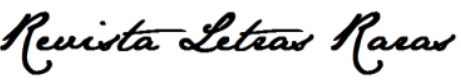

ISSN: 2317-2347 - v. 10, n. 4 (2021)

Todo o conteúdo da RLR está licenciado sob Creative Commons Atribuição 4.0 Internacional

Ainda segundo Paltridge (2012), a Análise de Necessidades compreende 3 acepções do termo 'necessidades'/ needs: 'exigências'/ necessities (determinadas pela situação-alvo, identificam aquilo que 0 aprendiz precisa saber e ser capaz de fazer para funcionar com efetividade na situação-alvo); 'lacunas'/lacks (o desnivel entre a proficiência existente e a proficiência almejada, considerando o que o aprendiz já sabe/já é capaz de fazer); e 'desejos'/wants (a visão dos aprendizes no que diz respeito ao que eles precisam saber/poder fazer com a/na língua-alvo).

E quanto aos modos de coletar informação para uma Análise de Necessidades, Paltridge (2012) enumera: revisão de literatura sobre Análise de Necessidades de um grupo levada a cabo previamente; conversa com pesquisadores experientes ou com grupos de aprendizes similares ao público-alvo em questão, ex-alunos, empregadores ou patrocinadores da Análise de Necessidades em pauta; obtenção de dados a partir do levantamento mediante questionários submetidos aos aprendizes, e entrevistas com os mesmos.

Observem que os três marcos teóricos sob o holofote aqui recuperados incluem, categoricamente, a Análise de Necessidades numa empreitada maior: o desenho ou a concepção curricular total. Esse será um ponto retomado ao longo do texto, quando a dificuldade de sua implementação efetivamente na nossa prática docente atual for abordada com maior destaque. Com o intuito de ilustrar como esse objeto de perquirição 'Análise de Necessidades' vem recorrendo na Linguística Aplicada recente, convido o leitor a conferir, p. ex. Araújo (2015), Brown (2016), Flowerdew (2014), Hutha et al. (2013), Johns e Makalela (2011), e Souza (2014).

Já Johns (2014, p. 9-10), ao traçar uma vista d'olhos na perquirição do tema 'Inglês para Fins Específicos', divide esse traçado em três fases, e insere na segunda delas o conceito de avaliação/ determinação/aferição de necessidades ("needs assessment"), precursor do termo "needs analysis" na literatura em Linguística Aplicada mundo afora. Os três momentos que a autora destaca são: 1. Contagens baseadas em textos e dispositivos retóricos inicialmente (entre 1962 e 1981); 2. Um alargamento de escopo num passado mais recente, com a introdução de categorias fulcrais, como a de 'avaliação/determinação/aferição de necessidades' (de 1981 a 1990); e 3. A "era moderna" (de 1990 à atualidade), em que prevalecem novos periódicos internacionais e abundam com proeminência investigações baseadas em gênero, raça e corpora, à la Fairclough (2013), entre outros. Nesse 


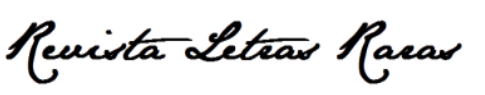

ISSN: 2317-2347 - v. 10, n. 4 (2021)

Todo o conteúdo da RLR está licenciado sob Creative Commons Atribuição 4.0 Internacional

contexto, merece ser citado o excerto que introduz o termo precursor do conceito 'Análise de Necessidades', a saber, o acima referido termo 'avaliação/determinação/aferição' de necessidades:

Durante os primeiros anos de publicação do Periódico Inglês para Fins Específicos (ESPJ), apareceram em número considerável artigos sobre avaliação/ determinação/aferição de necessidades, o cerne ou núcleo duro do trabalho do praticante de IFE (Inglês para Fins Específicos); embora, como West (1984) mostrou na discussão dela do Inglês como Segunda Língua Vocacional, a pesquisa em necessidades dos estudantes tivesse se tornado cada vez mais empírica, triangulada, e complexa ao longo do tempo. Jacobson (1986), também desbravando novas fronteiras, concentrou-se nas necessidades da competência estratégica, em vez de [focar] nas da competência gramatical ou discursiva dos estudantes num laboratório de física. Num contexto italiano, Tarantino (1988) usou um questionário de entrevista face-a-face para medir as necessidades em nível macro e micro de 53 estudantes e pesquisadores de ICT (Inglês para Ciência e Tecnologia). ${ }^{3}$ (JOHNS, 2014, p. 9-10)

Concluímos aqui a seção que visava à retomada dos marcos teóricos mais significativos na literatura de Linguística Aplicada no que tange ao objeto de inquirição do presente ensaio acadêmico. Passemos agora à parte aplicada do texto, em que analisaremos a viabilidade, ou ausência dela, de implementação desse ferramental na nossa prática docente cotidiana, dadas as circunstâncias laborais que nos circundam hoje.

\section{Os desafios que se nos apresentam}

3.1 0 gigantismo da macroestrutura de que a Análise de Necessidades inevitavelmente faz parte

Conforme já indicado, a Análise de Necessidades é somente uma das peças de um quebracabeça de imensidade quase incomensurável. Ela não está isolada, mas antes atrelada a toda uma engrenagem cuja configuração merece um olhar pormenorizado.

Nation e Macalister (2020, p. 2) apresentam tal engrenagem em um gráfico da seguinte maneira. Há 3 círculos menores ('necessidades', 'ambiente' e 'princípios') interligados em torno de um círculo central 'objetivos', o qual é trifacetado em 'conteúdo e sequenciamento', 'formato e apresentação', e 'monitoramento e controle'. E esse conjunto de quatro círculos é envolvido pelo círculo externo 'avaliação'. Segundo Nation e Macalister (2010), essas são as partes do desenho

\footnotetext{
${ }^{3}$ Transcrevendo a fonte primária, temos: "During these early years of ESPJ publication, there appeared a considerable number of articles on needs assessment, the core of ESP practitioner work; though as West (1984) showed in her discussion of vocational ESL (VESL), research into student needs had become increasingly empirical, triangulated and complex over time. Jacobson (1986), also breaking new ground, concentrated upon the strategic, rather than [focusing on] grammatical or discourse competence needs of students in a physics lab. In an Italian setting, Tarantino (1988) used a face-to-face questionnaire interview to measure the macro- and micro-level needs of 53 English for Science and Technology researchers and students."
} 


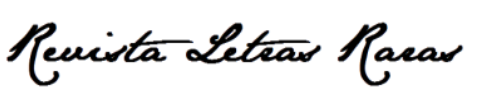

ISSN: 2317-2347 - v. 10, n. 4 (2021)

Todo o conteúdo da RLR está licenciado sob Creative Commons Atribuição 4.0 Internacional

curricular de uma língua. E o livro todo é dedicado a desenvolver os entrelaçamentos que essa configuração subentende. O círculo 'ambiente' é trifacetado em ‘aprendizes', 'professores' e 'situação'. O círculo 'necessidades' é trifacetado em 'exigências', 'lacunas' e 'desejos'. E o círculo 'princípios' é trifacetado nas mesmas dimensões que o círculo central 'objetivos', ou seja, compreendendo 'conteúdo e sequenciamento', 'formato e preparação', e 'monitoramento e controle'. Por ser tal esquema de difícil descrição verbal, ver, ao fim do ensaio, sua representação diagramática aqui replicada com autorização dos autores.

Semelhantemente, Flowerdew (2014, p. 326) assevera:

A Análise de Necessidades, levada a cabo para estabelecer "o quê" e "o como" de um curso, é a primeira etapa na concepção de um curso de Inglês para Fins Específicos, seguida de desenho de currículo, seleção de materiais, [decisão sobre / escolhas a respeito de] metodologia, sondagem e avaliação. Entretanto, esses estágios não devem ser vistos separadamente, procedendo em cadeia linear. Ao contrário, (...) eles são atividades interdependentes que se sobrepõem, num processo cíclico. ${ }^{4}$ (FLOWERDEW, 2014, p. 326)

E a linguista aplicada desenvolve todo o capítulo a resenhar as diversas abordagens que a Análise de Necessidades vem encampando desde o surgimento do subdomínio Inglês para Fins Específicos.

Por sua vez, Harwood e Petric (2011, p. 247) apresentam a 'Análise de Necessidades' como fator de uma constelação de estágios ao lado de 'análise de registro', 'análise discursiva e retórica', e 'habilidades exigidas pelo estudo', resgatando o quadro teórico que Dudley-Evans e St. John (1998) tinham apontado. Harwood e Petric (2011, p. 247) admoestam que seria, sem dúvida, por demais simplista ver esses estágios como discretos, uma vez que eles sempre se sobrepuseram, e elementos de cada estágio continuam a influenciar o pensamento na área de Inglês para Fins Acadêmicos (enquanto subárea de Inglês para Fins Específicos) até hoje, quer seja em um nível maior ou menor.

Também na Educação Básica, Técnica e Tecnológica verifica-se a atualidade onipresente da sondagem de Análise de Necessidades, conforme atestam, por exemplo, Suriano et al. (2016):

\footnotetext{
${ }^{4}$ Transcrevendo a fonte primária, temos: "Needs analysis, carried out to establish the 'what' and the 'how' of a course, is the first stage in ESP course development, followed by curriculum design, materials selection, [decision upon/choices over] methodology, assessment, and evaluation. However, these stages should not be seen as separate, proceeding in a linear fashion. Rather, as noted by Dudley-Evans and St. John (1998), they are interdependent overlapping activities, in a cyclical process."
} 


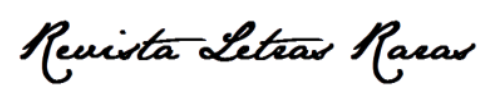

ISSN: 2317-2347 - v. 10, n. 4 (2021)

Todo o conteúdo da RLR está licenciado sob Creative Commons Atribuição 4.0 Internacional

Norteados pela urgência de se discutir o ensino-aprendizagem de línguas estrangeiras (inglês) em contextos de educação superior tecnológica, principalmente no que tange ao que lhe é específico, decidiu-se por identificar as necessidades ou demandas e os interesses de dois cursos superiores de tecnologia oferecidos por uma Faculdade de Tecnologia do interior do estado de São Paulo, Comércio Exterior e Logística. Optou-se por seguir uma metodologia de pesquisa de cunho qualitativo por meio de questionários enviados a empresas que atuam nas áreas dos referidos cursos, a alunos que atuam na área e a professores que ministram disciplinas nesses cursos. Também percorreu-se a bibliografia que estuda e discute o tema aqui proposto, e documentos que norteiam a criação dos cursos. Balizados pela resenha teórica acerca do Ensino de Línguas para Fins Específicos (ELFE), e com base nos resultados obtidos, podemos afirmar, circunscritos ao que nos propusemos estudar que, as necessidades das referidas áreas, em termos de habilidades linguísticas, remetem ao desenvolvimento da produção e compreensão escritas de documentos, contratos, fichas, manuais, relatórios e correios eletrônicos, para citar somente alguns [gêneros acadêmicos escritos / textuais], e à produção e compreensão orais em contextos de interação internacional com clientes, chefias e supervisores [ou consultores]. As dificuldades apontadas pelos participantes são as materializadas em necessidades ou demandas. ${ }^{5}$ (SURIANO ET AL., 2016, p. 01)

Vide ainda, no que diz respeito ao tema Análise de Necessidades sempre presente no contexto de educação superior tecnológica no Brasil, Vian Jr. (1999), Almeida Filho (2008), Ribeiro (2008), Ribeiro Jr (s/d)6 , Augusto-Navarro (2011), e Terenzi (2014).

\subsection{0 peso opressivo da ubiquidade do inglês no desenho da Universidade Federal do Sul da Bahia}

A UFSB é uma das mais recentes universidades públicas federais brasileiras. Criada em 2014, oriunda do movimento enérgico empreendido pelo governo Lula de interiorização ou capilarização da educação superior pública, gratuita e de qualidade, e com um desenho inovador, que se propõe a

${ }^{5}$ Transcrevendo a fonte primária, temos: "Guided by the urgency of discussing the foreign languages (English) teaching and learning in technological higher education contexts, especially in regard to what is specific to it, it was decided to identify the needs or demands and interests of the two upper (sic) courses of technology of the state of São Paulo. We chose to follow a research methodology of qualitative nature through questionnaires sent to companies operating in the areas of these courses, students working in the area, and teachers who teach subjects in these courses. Pertaining literature and documents that guide the creation of the courses have been analyzed, studied and discussed on this project, as well as a theoretical review about the specific purposes for language teaching (Language for Specific Purposes Teaching) was done. Based on the results, we can point out, focused on what we set out to study here, the needs of each area, in terms of language skills, referring to the development of production and understanding of written documents, contracts, forms, manuals, reports and e-mails, to name just a few [written academic or textual genre], and the oral production and listening skills in international contexts of interaction with customers, managers, supervisors [or consultants]. The difficulties identified by the participants are materialized in needs / demands."

${ }^{6}$ Apud Suriano et al. (2016), segundo Magali Barçante (comunicação pessoal). 


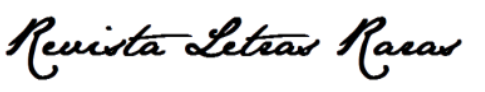

ISSN: 2317-2347 - v. 10, n. 4 (2021)

Todo o conteúdo da RLR está licenciado sob Creative Commons Atribuição 4.0 Internacional

mesclar o que há de mais revolucionário nos sistemas educacionais dos Estados Unidos, Canadá, Japão e Comunidade Europeia, e adaptar esse caldeirão cultural à realidade, à(s) demanda(s) específica(s) do (extremo) sul do nordeste brasileiro. Ela surge sobre pilares epistemológicos variados, tais como: os legados de Anísio Teixeira (universidade popular), Milton Santos (geografia nova), Paulo Freire (pedagogia da autonomia), Boaventura de Souza Santos (ecologia de saberes) e Pierre Lévy (inteligência coletiva). Corolário, prima por uma Instituição de Ensino Superior inclusiva, sem descuidar da excelência acadêmica, que mescla as demandas locais com uma formação preocupada com 0 global, na tentativa de oferecer à população do extremo sul e do sul da segunda região menos desenvolvida do país acesso à educação de excelência, que transforme cada estudante tão significativamente de modo que ele/a possa vir a contribuir eficaz e pragmaticamente para a construção de uma sociedade local, regional, nacional e mundial melhor.

Concebida em uma arquitetura multicampi (Itabuna, sede da Reitoria, o campus Jorge Amado, somada aos campi Sosígenes Costa, em Porto Seguro, e Paulo Freire, em Teixeira de Freitas), tentacularizada pelo interior das regiões metropolitanas em torno desses campi através da Rede de Colégios Universitários, os CUNIs, cujo ingresso de estudantes se dá mediante edital específico com um ponto de corte inferior ao ingresso nas sedes via Sistema de Seleção Unificada (SISU), ela permite aos estudantes egressos de trajetórias escolares sempre em escolas públicas desses rincões - os ditos vulneráveis sociais - adentrarem a UFSB por uma nota não tão alta no Exame Nacional do Ensino Médio (ENEM), comparada àquela exigida para o ingresso nas sedes pelo caminho do SISU. Além disso, é a Instituição Federal de Ensino Superior (IFES) que mais enfatiza a política de ações afirmativas capitaneada pelo Ministério da Educação e Cultura (MEC) recentemente, uma vez que $85 \%$ dos nossos ingressantes são categorizados em uma ou mais faixa das seguintes minorias: indígenas, quilombolas, transexuais, pessoas com deficiência (os antes ditos "especiais"), e/ou economicamente vulneráveis sociais, acima referidos.

Funcionando em regime letivo quadrimestral multiturno, e sustentada em um programa de ciclos de formação com modularidade progressiva, a UFSB confere certificações periódicas após o $1^{0}$ ano de estudos comum a todos os estudantes, a dita Formação Geral, seguida de diplomas de primeiro ciclo após mais dois anos de estudos abrangentes mais focados em torno de uma área específica do conhecimento em Bacharelados Interdisciplinares (Bls) ou Licenciaturas Interdisciplinares (LIs). Os 


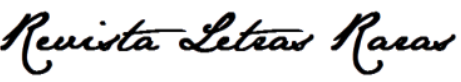

ISSN: 2317-2347 - v. 10, n. 4 (2021)

Todo o conteúdo da RLR está licenciado sob Creative Commons Atribuição 4.0 Internacional

Bls são oferecidos em quatro grandes áreas de formação (Ciências, Artes, Humanidades e Saúde). As LIs são oferecidas para ensino de Artes, ensino de Ciências, ensino de Humanidades, ensino de Matemática e Computação, e ensino de Linguagens e suas Tecnologias.

Concluído o primeiro ciclo, o/a estudante pode optar por mais um período de formação específica - de perspectiva eminentemente profissionalizante - para a área de conhecimento de sua escolha (o $2^{\circ}$ ciclo), ou tentar ingresso diretamente no $3^{\circ}$ ciclo, que abrange tanto programas de especialização ou aperfeiçoamento/atualização (cursos de pós lato sensu) quanto de mestrado acadêmico ou profissional e, em seguida, avançar para o doutorado (essas últimas três opções consistindo em cursos de pós stricto sensu).

A UFSB enfatiza a construção do conhecimento através de metodologias ativas, equipes colaborativas de trabalho, aprendizagem baseada na resolução de problemas concretos, 0 apoio massivo em tecnologias da informação e da comunicação, a proeminência do desenvolvimento científico sustentável, que não cause mais desequilíbrio aos biomas do meio ambiente do que o ser humano primata, capitalista selvagem vem há muito ocasionando ao planeta, e o domínio da língua inglesa enquanto ferramental indispensável aos cidadãos da aldeia global para que se empoderem e consigam ter voz na sociedade em que o inglês é, sem dúvida, o idioma mais usado no intercâmbio científico e cultural entre os povos, na Terra do $3^{\circ}$ milênio mundializada em que vivemos.

Assim sendo, inscritos em seus documentos basilares (Plano Orientador, Carta de Fundação, Regimento Interno, Plano de Desenvolvimento Universitário e Projetos Pedagógicos de Curso de todos os Bls e de todas as Lls), componentes curriculares de língua inglesa de natureza instrumental são requeridos (em caráter obrigatório ou optativo, a depender do percurso formativo de cada estudante) para o alunado da UFSB transversal e longitudinalmente. E tal demanda cresce em espiral à medida que os estudantes avançam da Formação Geral para $01^{10}$ ciclo de formação específica, e daí para $02^{\circ}$ e $3^{\circ}$ ciclos, cada vez mais afunilados. Além disso, os/as estudantes da Licenciatura Interdisciplinar em Linguagens esperam do meu Colegiado de Curso até hoje a oferta de Componentes Curriculares de língua inglesa 4 habilidades, por enquanto represada por falta de fôlego para atendermos tal expectativa, para que se formem em futuros professores de ILE mais bem preparados para exercer sua função no mercado de trabalho. É o inglês para formação de professores, do qual pretendemos - eu e os demais colegas do ILE da UFSB - lograr nos ocupar a partir do ano letivo 2022. 




ISSN: 2317-2347 - v. 10, n. 4 (2021)

Todo o conteúdo da RLR está licenciado sob Creative Commons Atribuição 4.0 Internacional

Resulta dessa demanda onipresente por inglês para leitura que o plano de expansão gradativa da Universidade previa, para até o fim de 2020, enquanto meio termo entre o período de implantação (2014-2018) e o de consolidação (2019-2023), um corpo docente de língua inglesa de 6 membros por campus. Entretanto, até o passado muito recente de março de 2018 , só havia o autor do presente ensaio acadêmico enquanto concursado para Leitura e Produção de Textos em Língua Inglesa, o que me obrigava a selecionar periodicamente colegas professores substitutos / temporários para remediar no limite essa situação de penúria no quadro laboral específico da área de inglês. A partir de março de 2018, conto - enquanto líder intercampi da subárea Língua Inglesa da Licenciatura Interdisciplinar em Linguagens e suas Tecnologias da Casa - com a presença de 5 colegas, concursados e "pulverizados" pelos outros 2 campi (3 no CJA e 2 no CPF).

Em síntese, de 2014 a 2018 vivemos os 5 primeiros anos da ancoragem da UFSB no território do sul e do extremo sul do estado. E desde então, adentramos a etapa de atracagem dessa fixação, se me permitem uma metáfora náutica, que compreende os 5 anos subsequentes a esse período, qual seja, de 2019 a 2023. Acumulando as funções de vice-coordenador da LIL (Licenciatura Interdisciplinar em Linguagens) no CPF (Campus Paulo Freire) durante os 2 primeiros anos de prestação de serviços na Casa, e, desde a minha remoção para o CSC (Campus Sosígenes Costa), as de vice-coordenador da LIL desse campus, de vice-presidente do NDE (Núcleo Docente Estruturante) da LIL CSC, e a de vice-representante docente junto à Congregação do Centro de Ciências Humanas e Sociais da UFSB, tenho enfrentado, enquanto decano intercampi de ILE da IFES, o ônus da responsabilidade gigantesca de preparar, planejar e implementar de forma protagonista o estabelecimento da fundação e de erguer o edifício da língua inglesa sobre ela tanto para todos os cursos, enquanto Inglês Instrumental / para Fins Acadêmicos / para Fins Específicos, como também enquanto inglês 4 habilidades, para os nossos estudantes da LIL que se interessem pela condução da aula de língua estrangeira inglês posteriormente no mercado de trabalho.

Atentem para o fato de que, dado o estrangulamento do nosso corpo docente, decorrente da vil campanha do governo federal que assumiu pós-golpe (impedimento sem justa causa da Presidenta Dilma Rousseff) de catalisar o desmonte das IFES públicas nacionais, e de suas contrapartes estaduais/municipais também - que já sofriam com a "PEC da morte" (a proposta de emenda constitucional do teto dos gastos) e passaram a agonizar ainda mais com a inviabilização de novos 




ISSN: 2317-2347 - v. 10, n. 4 (2021)

Todo o conteúdo da RLR está licenciado sob Creative Commons Atribuição 4.0 Internacional

concursos para docentes, o fazer laboral do autor deste texto e de seus colegas de área na UFSB fica cada vez mais sobremaneira obstaculizado. As condições para o adoecimento docente são, portanto, evidentes. Haja vista as iniciativas nessa contracorrente empreendidas nos 3 campi, a saber: 0 LABPICS (Laboratório de Práticas Integrativas e Complementares de Saúde), da Profa. Dra. Isabel Belasco no CSC; a sondagem do estado de saúde ou da qualidade de vida física e psicológica dos docentes da UFSB, levada a cabo pela Profa. Dra. Sandra Nunes no CJA (Campus Jorge Amado); e as iniciativas Massoterapia para o Bem-Estar dos professores, técnicos e estudantes do CPF, (Campus Paulo Freire) projeto de extensão desenvolvido pelo Prof. Dr. Leandro Gaffo com vários estudantes bolsistas, englobando vários tipos de massagens, tanto ocidentais como orientais, em Teixeira de Freitas, bem como os canteiros de fitoterapia como insumo para o equilíbrio corporal e espiritual a partir do mini-horto do CPF, liderados pelas Profas. Dras. Thayna Müller e Gisele Lopes naquele campus.

\section{Considerações finais}

Neste ensaio acadêmico me propus a detalhar o quão premente se revela a materialização de uma tão desejada Análise de Necessidades na minha prática docente de ILE (Inglês Língua Estrangeira) na UFSB, bem como intentei arrolar os entraves que dificultam bastante o levar a cabo essa tarefa, por enquanto, relacionados tanto com a magnitude de um programa de concepção curricular da qual a Análise de Necessidades impreterivelmente faz parte, seja na IFES em que ora trabalho, seja alhures, quanto também com a escassez momentânea de mão de obra especificamente concursada para Leitura e Produção de Textos em Língua Inglesa que ainda gravemente acomete a jovem Instituição de Ensino Superior a que ora me afilio.

Quanto àquela dificuldade, lembremos Kubota e Chiang (2014, p. 483), que, ao lado da contestação do pragmatismo das abordagens contemporâneas de Análise Crítica do Discurso em sua interação com a subárea Inglês para Fins Específicos, arrolam como outro tema contencioso no âmbito de tal linha perquiritória a inserção da Análise de Necessidades nesse fazer laboral. Afinal, encurtando bem 0 assunto em prol da objetividade, mas não a ponto de correr o risco de deixar que o poder de síntese torne a retomada ininteligível ou peque pelo obscurantismo, 




ISSN: 2317-2347 - v. 10, n. 4 (2021)

Todo o conteúdo da RLR está licenciado sob Creative Commons Atribuição 4.0 Internacional

[...] embora qualquer ensino seja e deva ser mesmo construído a partir de certas necessidades, o ensino de Inglês para Fins Específicos coloca em primeiro plano a consciência de necessidades específicas que existem em uma instituição, uma profissão, ou um indivíduo em particular. ${ }^{7}$ (KUBOTA; CHIANG, 2014, p. 483)

Como saída possível para esse impasse, referido no início do texto sob a metáfora face de Jano, à guisa de conciliação, talvez o melhor mesmo seja enfileirar-me com Hirvella (1998) e com Belcher (2006, p. 139) e defender que o mais sensato e eficiente a se fazer, pelo menos por ora, enquanto o quadro completo de 6 professores da área por campus que o plano de expansão integral da UFSB em seu desenho original vislumbra como configuração ideal não se torna realidade, é mesmo decidir que os estudantes de graduação sem um curso estritamente definido - realidade que bem se enquadra nos de nossos Bls e LIs de $1^{\circ}$ ciclo - possam se beneficiar com uma abordagem de amplo espectro no que tange ao ILE de cunho genericista.

Em suma, muito embora, por razões metodológico-didático-pedagógicas, fosse desejável proceder a uma Análise de Necessidades antes do processo de ensino-aprendizagem deslanchar com toda e qualquer turma de estudantes de ILE, não é exequível fazê-lo (ainda?) no meu atual emprego, dada a escassez de docentes efetivos na área que a UFSB possui hoje. Isto é, por ser o plantel de ILE na IFES ainda por demais reduzido, que até bem pouco tempo se limitava unicamente a mim enquanto membro concursado para tal, coordenando uma equipe temporária de 6 docentes substitutos de inglês em toda a estrutura multicampi da UFSB; e atualmente conta ao todo com meros 6 docentes efetivos dessa área dispersos pelos 3 campi, parece de fato prudente aceitar que o que nos resta fazer, mantendo a qualidade requerida no ensino-pesquisa-extensão das universidades públicas brasileiras, é optar hoje por cursos de Inglês para Fins Acadêmicos generalistas, que cubram textos tematicamente relativos aos diversos campos do saber que englobam todos os Bls e Lls do nosso alunado, e deixar cursos mais customizados, elaborados sob medida para atender ao diagnóstico de Análise de Necessidades proveniente de cada subgrupo individualizado de estudantes, talhados, enfim, a partir da Análise de Necessidades de cada turma que se nos apresente, a mim e aos demais colegas da área, como desideratum para os/as estudantes de $1^{\circ}, 2^{\circ}$ e $3^{\circ}$ ciclos a que nos dedicaremos eventualmente, quando formos - e oxalá tal configuração laboral ideal se efetive em

7 Transcrevendo a fonte primária, temos: "Although any teaching is and should be built upon certain needs, teaching ESP foregrounds the awareness of the specific needs that exist in a particular institution, profession, or individual." 




ISSN: 2317-2347 - v. 10, n. 4 (2021)

Todo o conteúdo da RLR está licenciado sob Creative Commons Atribuição 4.0 Internacional

breve / um dia, mesmo que num futuro mediato ou distante, dada a conjuntura adversa que assola a contemporaneidade recente no Brasil e em boa parte do mundo - dotados de pessoal especificamente treinado para esse mister suficientemente mais numeroso e, logo, robusto. Fiquemos então, por ora, com um inglês para fins acadêmicos de cunho genericista, a que chamei neste ensaio "Inglês Geral para Fins Específicos"!

\section{Agradecimentos}

Gostaria de deixar aqui registrada a minha gratidão a 3 parceiros internacionais de investigação científica: Professores Diane Belcher, Nigel Harwood e Brian Paltridge, que gentilmente me cederam artigos de sua autoria para consubstanciar o embasamento teórico deste ensaio acadêmico. Por fim, mas em absoluto não menos importante, meu mais sincero muito obrigado à Profa. Dra. Aparecida de Araújo Oliveira, da UFV, que leu uma versão pregressa deste texto e contribuiu com valiosíssimas observações para que eu o aprimorasse, como de costume. E também ao meu colega atual de trabalho Prof. Dr. Nadson Reyssé Simões, que funcionou como editor ad hoc número 2 voluntário de uma versão preliminar do ensaio acadêmico antes de eu submetê-lo à Revista. Nem preciso dizer que as deficiências que por ventura nele persistirem continuam sendo de minha única e inteira responsabilidade, estando todos os colaboradores isentos de qualquer incongruência que eu não tiver sido capaz de eliminar no meu texto, apesar de seus eventuais ensinamentos e apontamentos.

\section{Referências}

ALMEIDA FILHO, J. C. P. Aprendizagem e ensino de línguas em contextos tecnológicos. Revista Reverte - Revista de Estudos e Reflexões Tecnológicas da FATEC - Indaiatuba. v. 6, 2008.

ARAÚJO, M. Inglês para fins específicos: o desenho de um curso a partir da análise de necessidades. Intercâmbio, vol. 30, p. 51-79, 2015.

AUGUSTO-NAVARRO, E. H. Os novos rumos do English for Specific Purposes. 2011. Disponível gratuitamente em linha: http://ww.sala.org.br/index.php/videos/229-os-novos-rumos-de-english-forspecific-purpose. Acesso em: 19 jun 2019.

BELCHER, D. English for Specific Purposes: Teaching to perceived needs and imagined futures in worlds of work, study, and everyday life. TESOL Quarterly, vol. 40, number 1, p. 133-56, 2006.

What ESP is and can be: An introduction. In D. Belcher (ed.) English for specific purposes in theory and practice. Ann Arbor: University of Michigan Press, p. 1-20, 2009. 




ISSN: 2317-2347 - v. 10, n. 4 (2021)

Todo o conteúdo da RLR está licenciado sob Creative Commons Atribuição 4.0 Internacional

BROWN, D. Introducing needs analysis and ESP. London: Routledge, 2016.

CELANI, A. When myth and reality meet: Reflections on ESP in Brazil. ESP 27, 4, p. 412-23, 2008.

CHALHUB, S. Funções da linguagem. Série Princípios, 119. São Paulo: Editora Ática, 2006.

CHAMBERS, F. A re-evaluation of needs analysis in ESP. ESP Journal, 1/1, 25-33, 1980.

COLEMAN, H. Programme Development for Learners of English. In R. Richterich (ed.) Case studies in identifying language needs. Oxford: Pergamon, 79-87, 1988.

DELLA ROSA, S. F. Análise das reflexões estabelecidas por pesquisadores entre conhecimento de língua inglesa e desempenho acadêmico. Dissertação de Mestrado em Linguística. Universidade Federal de São Carlos, 2013, 148 pp.

DUDLEY-EVANS, T.; ST. JOHN, M. Developments in ESP: An interdisciplinary approach. Cambridge, UK: Cambridge University Press, 1998.

FAIRCLOUGH, N. Critical discourse analysis: The critical study of language. London: Routledge, 2013. Second revised, updated and enlarged edition.

FLOWERDEW, L. Needs analysis and curriculum development in ESP. In B. Paltridge; S. Starfield (eds.) The handbook of ESP. Malden, MA: Wiley/Blackwell, p. 325-46, 2014.

HARWOOD, N.; PETRIC, B. English for Academic Purposes. In J. Simpson (ed.) Handbook of applied linguistics. London: Routledge, p. 246-61, 2011.

HAWKEY, R. Programme development for learners of English. In R. Richterich (ed.) Case studies in identifying language needs. Oxford: Pergamon, Council of Europe, p. 79-87, 1983.

HIRVELA, A. Review of Myra Schulman's Journeys through literature. English for Specific Purposes, 17, p. 320-26, 1998.

HUTCHINSON, T.; WATERS, A. ESP: A learner-centred approach. Cambridge, UK: Cambridge University Press, 1987.

HUTHA, M.; VOGT, K.; JOHNSON, E.; TULKKI, D. Needs analysis for language course design: A holistic approach to ESP. Edited and with an introduction by D. R. Hall. New York: Cambridge University Press, 2013.

JACOBSON, W. An assessment of communication needs on non-native speakers of English in an undergraduate physics lab. English for Specific Purposes 7: 55-60, 1986.

JAKOBSON, R. Lingüística e comunicação. São Paulo: Cultrix, 1969.

JOHNS, A. The history of English for Specific Purposes research. In B. Paltridge; S. Starfield (eds.) The handbook of English for Specific Purposes. Malden, MA: Wiley/Blackwell, p. 5-30, 2014.

JOHNS, A.; MAKALELA, L. Needs Analysis, critical ethnography, and context: Perspective from the client and the consultant. In D. Belcher; A. M. Johns; B. Paltridge (eds.) New directions in ESP research. Ann Arbor: University of Michigan Press, p. 197-221, 2011.

JORDÃO, C. ILA - ILF - ILE - ILG: Quem dá conta? EAL - ELF - EFL - EGL - Same difference? RBLA, Belo Horizonte, vol. 14, no 1, p. 13-40, 2014. 


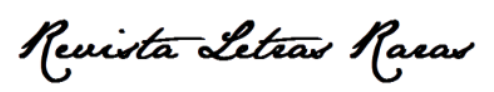

ISSN: 2317-2347 - v. 10, n. 4 (2021)

Todo o conteúdo da RLR está licenciado sob Creative Commons Atribuição 4.0 Internacional

KUBOTA, R; CHIANG, L. Gender and race in ESP research. In B. Paltridge; S. Starfield (eds.) The handbook of English for Specific Purposes. Malden, MA: Wiley/Blackwell, p. 481-99, 2014.

MACKAY, R. Identifying the nature of the learner's needs. In A. Mackay; A. Mountford (eds.) English for specific purposes. London: Longman, p. 21-37, 1978.

MCDONOUGH, J. Needs analysis. In K. Johnson; H. Johnson (eds.) Encyclopedic dictionary of applied linguistics. Oxford, UK: Blackwell, p. 228-30, 1999.

MARKEE, N. Towards an appropriate technology model of communicative course design: issues and definitions. English for Specific Purposes, 5/2, p. 161-72, 1986.

MENDES, V.S. Needs analysis and the teaching-learning of EFL at the youngest public federal university in Brazil. Paper given at the IV SEFELI (Seminário Formação de Professores e Ensino de Língua Inglesa). Aracaju, Sergipe Federal University, 2018.

MUNBY, J. Communicative syllabus design. Cambridge, UK: Cambridge University Press, 1978.

NASH, M. G.; FERREIRA, W. R. Real English: Vocabulário, gramática e funções a partir de textos em inglês. Barueri, SP: Disal, 2010.

NATION, I. S. P.; MACALISTER, J. Language curriculum design. New York and London: Routledge, 2020. $2^{\text {nd }}$ updated and revised edition.

PALTRIDGE, B. Teaching English for Specific Purposes. In A. Burns; J. Richards (eds.) The Cambridge guide to pedagogy and practice in second language teaching. New York: Cambridge University Press, p. 179-85, 2012.

PILBEAM, A. The language audit. Language Training 1/2, 593, 1979.

RAMOS, R. Instrumental no Brasil: desconstrução de mitos e construção do futuro. In M. M. Freire; M. H. V. Abrahão; A. M. F. Barcelos (orgs.) Lingüística aplicada e contemporaneidade. São Paulo: ALAB; Campinas: Pontes, p. 109-23, 2005.

RIBEIRO, M. Aspectos culturais no contexto empresarial globalizado: novos desafios para o professor de língua estrangeira (inglês). Revista Reverte, vol. 6, 2008.

RIBEIRO JR., J. A. Análise de necessidades no meio empresarial: o uso da língua inglesa em logística. Trabalho de conclusão de curso de graduação em nível superior em gestão empresarial com ênfase em logística aeroportuária. S/d. Disponível online em www.fatecid.com.br

RICHARDS, J.; SCHMIDT, R. Longman dictionary of language teaching and applied linguistics. Malasya: Pearson, 2010, $4^{\text {th }}$ updated edition.

RICTHERICH, R. (ed.) Case studies in identifying language needs. Oxford: Pergamon, 1983.

RICHTERICH, R.; CHANCEREL, J.-L. Identifying the needs of adults learning a foreign language. Oxford: Pergamon, 1980.

ROBINSON, P. C. ESP today: A practitioner's guide. New York: Prentice Hall, 1991. 


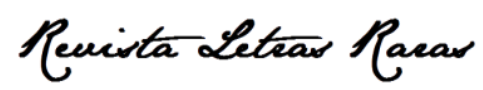

ISSN: 2317-2347 - v. 10, n. 4 (2021)

Todo o conteúdo da RLR está licenciado sob Creative Commons Atribuição 4.0 Internacional

SIQUEIRA, S. World Englishes, world English, inglês como língua internacional, inglês como língua franca. In X. C. Lagares; M. Bagno (orgs.). Políticas da norma e conflitos linguísticos. São Paulo: Parábola, p. 333-54, 2011.

SOUZA, S. Análise de necessidades e o ensino de línguas para fins específicos. Revista Desempenho, número 22, s/ pp. na publicação em linha, 2014.

SURIANO, F. A. et al. Ensino de inglês nos cursos de tecnologia: interesses e necessidades para 0 desenvolvimento de conteúdo específico. Reverte n.14, 1-11, 2016.

TARANTINO, M. Italian in-field EST users self-assess their macro- and micro-level needs. A case study. English for Specific Purposes 7: 33-54, 1988.

TERENZI, D. Inglês para propósitos específicos no ensino superior tecnológico: Relações entre as percepções dos aprendizes, a proposta da instituição formadora e as demandas dos empregadores. Tese de doutorado. São Carlos: UFSCar, 2014.

THOMPSON, M. A. Inglês instrumental: Estratégias de leitura para informática e internet. São Paulo: Érica/Saraiva, 2016.

VIAN JR. O. Inglês instrumental, inglês para negócios e inglês instrumental para negócios. São Paulo. DELTA, vol. 15, nº especial, 437-57, 1999.

WEST, L. Needs assessment in occupation-specific VESL, or how to decide what to teach. The ESP Journal 3: 143-52, 1984.

WEST, R. Needs analysis in language teaching. State of the art article. Language Teaching 27 (1), 119, 1994.

Anexo A: model of the parts of the curriculum design process (um modelo das partes do processo de desenho curricular)

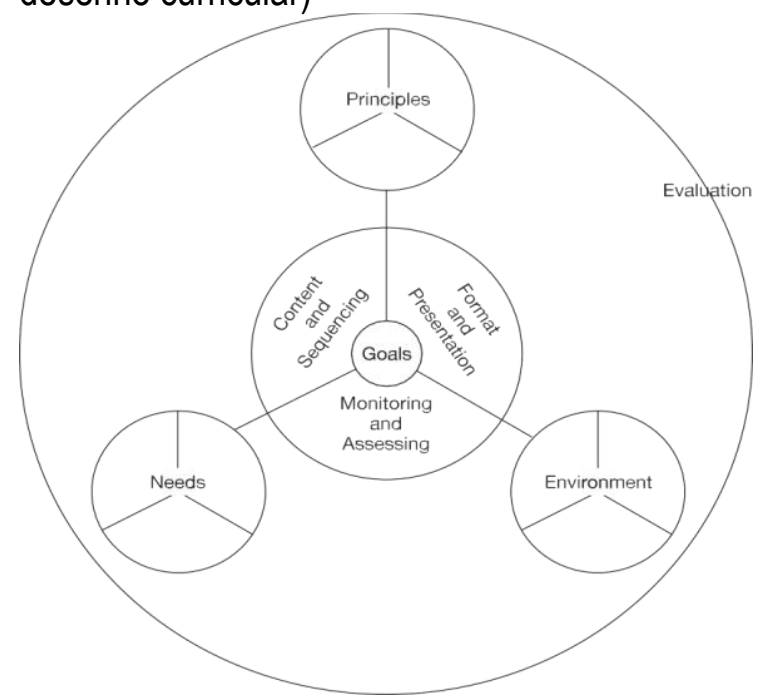

Fonte: Nation; Maclister (2020, p. 2) 